\title{
Optical properties of zinc borotellurite glass system doped with erbium and erbium nanoparticles for photonic applications
}

\begin{abstract}
Comparative analysis on optical properties between two glass series (að ordinary glass, bð glass with nanoparticles) have been estimated. The two glass series (að ordinary glass, bठ glass with nanoparticles) with compositions $\{[(\mathrm{TeO} 2) 0.70(\mathrm{~B} 2 \mathrm{O} 3) 0.30] 0.70(\mathrm{ZnO}) 0.30\} 1 \overline{\mathrm{i}} \mathrm{y}$ (Er2O3/Er2O3 nanoparticles)y; $y=0.005,0.01,0.02,0.03,0.04,0.05 \mathrm{~mol} \%$ were successfully prepared by using melt-quenching method. The TEM, EDX and XRD have been used to confirm the existence of nanoparticles and all elements in the glass system. The density of bठ glass with nanoparticles are found greater than að ordinary glass. The optical properties of the glass series were characterized by using Ellipsometer and UVï Vis spectrophotometer. There is a linear increasing trend in refractive index of the glass series along with concentration of erbium and erbium nanoparticles oxide. The refractive index of bð glass with nanoparticles is greater than að ordinary glass. Moreover, the absorption peaks of að ordinary glass are more intense than bð glass with nanoparticles. The glass with nanoparticles will offer a potential materials for nanophotonic devices.
\end{abstract}

Keyword: Optical properties; Erbium; Nanoparticles; Glass; Photonic application; Zinc borotellurite glass 